\title{
Experimental investigation and performance analysis of triple concentric helical tube heat exchanger
}

\author{
M. Sahoo ${ }^{\# 1}$, V.M. Behera ${ }^{\# 2}$, S.N.Das ${ }^{* 3}$,H.C.Das ${ }^{\# 4}$ \\ \#1,\#3,\#4 Mechanical Department, SOA University \\ ${ }^{\# 2}$ Mechanical Department, BPUT \\ ${ }^{1}$ monalisa.liza.2012@gmail.com, ${ }^{2}$ vishwamohan_behera@yahoo.com, ${ }^{4}$ harishdas@soauniversity.ac.in \\ 3 sankardas@soauniversity.ac.in
}

\begin{abstract}
An experimental investigation for helical triple concentric tube heat exchanger has been carried out with different flow arrangements i.e. N-H-C (normal fluid inside - hot at middle - cold in outer annulus) and C-H-N (cold fluid in inner pipe - hot in middle - normal fluid in outer annulus) with parallel and counter flow types. The temperature distribution of fluids w.r.t. length of the heat exchanger has been observed. Effectiveness is calculated for parallel and counter flow in NHC and CHN arrangements. The triple concentric helical tube heat exchanger proved to be effective and of compact design for heat exchange between the fluids. The N-H-C counter flow arrangement with high volume flow rate of fluid proved to be effective than other arrangements.
\end{abstract}

Keywords: triple concentric; helical tube; N-H-C; C-H-N

\section{INTRODUCTION}

Heat exchangers due to its broad area of applications have been always a challenge for researchers. Over a decade tremendous effort has been done over boosting of the performance of heat exchangers by approaching several techniques, designing parameters and models. The design of heat exchanger has become critical due to its compactness in size and competitive cost of manufacturing. Different techniques have been implemented to meet the cost effectiveness and maximize the performance of heat exchangers with compactness of the device.

L. Godson et al.[1], carried out an experimental analysis with silver/ water nanofluids in a shell and tube heat exchanger. The results showed that there is an increase in convective heat transfer coefficient and effectiveness of silver/water nanofluids as the particle volume concentration was increased. A numerical investigation on the shell side heat transfer and pressure drop performances of twisted oval tube heat exchanger was done by Xiang-hui Tan et al. [2], comparing the numerical results with the experimental one and concluded that heat transfer and pressure drop differences were $4.01 \%$ and $3.98 \%$, respectively. In a similar way tube side and shell side heat transfer and pressure drop performances of a twisted oval tube heat exchanger has been experimentally studied by Xiang-hui Tan etal.[3]. The comparative study shows that the heat transfer coefficient of the twisted oval tube heat exchanger is higher and the pressure drop is lower than the rod baffle heat exchanger. Heat transfer enhancement by flow-induced vibration in heat exchangers were studied experimentally by L. Cheng et al.[4], from the results an increase in the convective heat transfer coefficient and decrease in the fouling resistance was noticed for the arrangement. N. Sahiti et al. [5] studied the heat transfer enhancement of heat exchanger by pin elements and found an improved effectiveness of the heat exchanger.

The heat transfer enhancement of nanofluids in a double pipe heat exchanger by using louvered strip inserts was studied numerically by H.A. Mohammad et.al.[6],from the results it was observed that and $\mathrm{SiO}_{2}$ nanofluid has the highest Nusselt number and skin friction coefficient values and pure water has the lowest Nusselt numbervalues.E. K. Akpinaretal. [7] have investigated experimentally the effect of heat transfer rates, friction factor and exergy loss of swirl generators with holes for the entrance of fluid by placing them at the entrance section of inner pipe of heat exchanger. The results emphasized an increase in the nusselt number and effectiveness by using swirl generator. Yu et.al, [8] have studied experimentally the heat transfer and pressure drop characteristics between blocked tubes and unblocked tubes having a double pipe structure, with the inner tube as an insertion. From the results it has been found that wave like fins could enhance heat transfer significantly with the blocked case being superior. Second law analysis on the heat transfer was done on a horizontal concentric tube heat exchanger at different flow rate condition and different inlet temperature condition by PaisarnNaphon. [10] In this study the results showed that the volume flow rate and temperature have significance effect on the entropy generation, entropy generation number and exergy loss.

The pressure drop and convective heat transfer characteristics of water and five alumina/water nanofluids of weight concentrations of $0.78 \%$ wt., $2.18 \%$ wt., $3.89 \%$ wt., $5.68 \%$ wt., and $7.04 \%$ wt. were experimentally 
investigated byZan Wu etal. [15] for both laminar flow and turbulent flow inside a double pipe helically coiled heat exchanger, they reported that heat transfer enhancement of the nanofluids compared to water is from $0.37 \%$ to $3.43 \%$ according to the constant flow velocity. Experimental analysis of heat transfer enhancement in shell and helical tube heat exchangers was investigated by N. Jamshidi et al. [16], an optimum condition for increasing overall heat transfer coefficient in coiled tube heat exchanger was obtained by highest level of the coil diameter, coil pitch, hot and coldwater flow rates. An experimental investigation of the mixed convection heat transfer in a coil-in-shell heat exchanger was reported by Nasser Ghorbani et al. [17] for various Reynolds and Rayleigh numbers, various tube-to-coil diameter ratios and dimensionless coil pitch. It was found that the volume flow rate of tube-side to shell-side ratio was effective on the axial temperature profiles of heat exchanger .An experimental study was carried out by Yang Dong et al. [18] to determine the pressure drop, heat transfer and performance of single phase turbulent flow in spirally corrugated tubes. The result showed that thermal performances of these corrugated tubes are superior than the smooth tube. The effects on heat transfer, friction factor and dimensionless exergy loss were investigated experimentally by E.K. Akpinar by mounting helical (spring shaped) wires of different pitch in the inner pipe of double pipe heat exchanger. Increases in nusselt number and exergy loss were obtained as compared to empty tube [19].

The helical coils are very alluring for various processes such as heat exchangers and reactors because they can accommodate a large heat transfer area in a small space, with high heat transfer coefficients and narrow residence time distributions.

AhmetUnal.[11,12] in his research have made a theoretical approach for triple concentric tube heat exchanger by deriving governing equations and represented its performance analysis on both triple tube and counter flow type double tube heat exchangers. Numerical evaluation of triple concentric-tube latent heat thermal energy storage was done by Birol Basal et al.[13], the results showed a major rise in the system performance by replacing a classical hollow cylinder type storage with the presently proposed triple concentric-tube storage system. Experimental investigations were done by G.A. Quadir et al.[14] for triple concentric pipe heat exchanger for two different flow arrangements such as N-H-C and C-H-N condition and for insulated and noninsulated condition of the heat exchanger.

In the present research, a new design concept of helical triple concentric tube heat exchanger is proposed. From the investigation substantial enhancement in heat transfer between the fluids is observed. In the experimental study for the temperature distribution of three fluids along the length of heat exchanger and the effects of different flow arrangements with different volume flow rates are carried out on the helical triple tube heat exchanger.

\section{Experimental apparatus and procedure for a helical triple tube heat exchange:}

Schematic diagram of the experimental apparatus as shown Figure 1(a) and(b) the heat exchanger is a concentric tube heat exchanger which is consists of two annulus and one helical pipe. The inner pipe is made up of brass (ASTM B135), middle helical pipe is made of copper (ASTM B88) and outer pipe is made of steel (ASTM A249) for cost economical design. The inner diameters of the inner pipe, helical and outer pipes are $28.75 \mathrm{~mm}, 12.87 \mathrm{~mm}$ and $98.4 \mathrm{~mm}$ respectively with thickness of each pipe as $1.5 \mathrm{~mm}$.

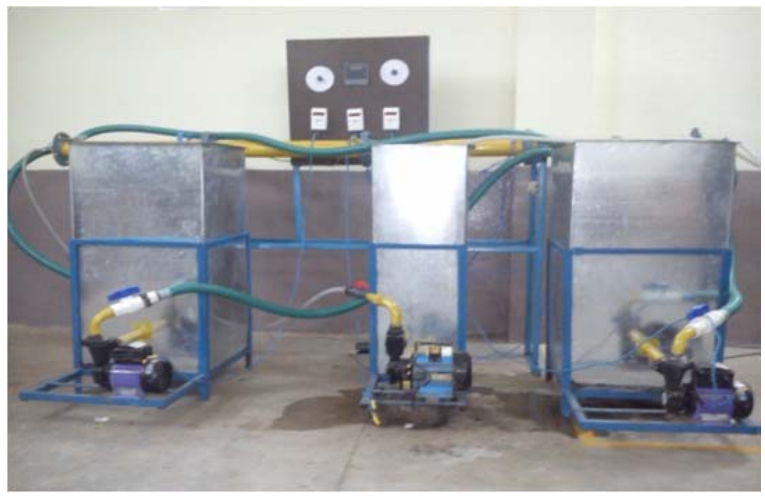

Fig 1(a): Experimental setup of triple concentric helical (TCH) pipe heat exchanger.

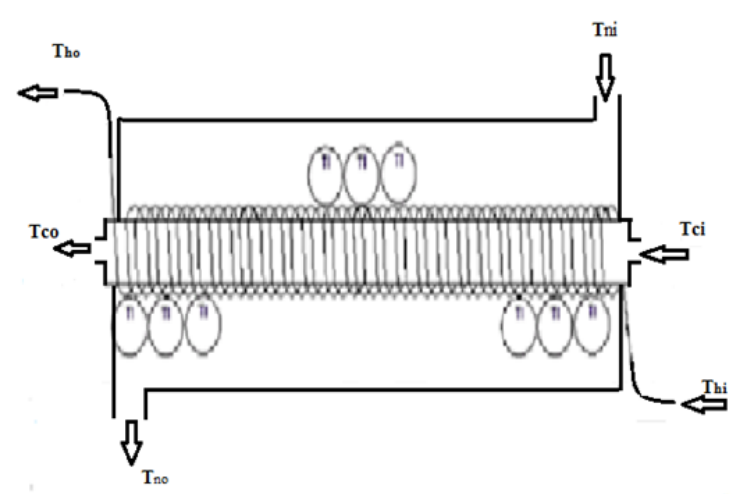

Fig.1(b): Schematic diagram for TCH pipe heat exchanger with c-h-n parallel flow.

The experimental set up is composed of test section, normal water flow passage, cold water flow passage, hot water flow passage and temperature measuring system. The design of heat exchanger is made in such a way that different flow configuration can be arranged by changing the pipe connections. The hot water passage 
consists of a storage tank, an electric heater of $3000 \mathrm{~W}$ immerged inside the storage tank to obtain desired temperature of hot water, a pump and gate valve. The cold water passage consists of a storage tank, a pump and gate valve. Ice cubes are used to cool down the temperature of tap water to nearly $13^{0} \mathrm{C}$. The path of each fluid consists of rotameter. The flow rate of the water are controlled by adjusting the gate valve and measured by the flow metres. The water temperatures at inlet, outlet and at different sections of the tubes are measured by the $T$ copper-constantan thermocouple probes. Water temperatures of the inner tubes are measured by mounting the thermocouple probes in the tubes. The flow of three working fluids hot water, normal water and cold water are maintained by the arrangement of three pumps in the heat exchanger.

Ice cubes are used to cool down the temperature of tap water to nearly $13^{0} \mathrm{C}$. The normal water loop consists of storage tank, pump and gate valve. The flow rate of the water are controlled by adjusting the gate valve and measured by the flow metres. The water temperatures at inlet, outlet and at different sections of the tubes are measured by the $\mathrm{T}$ copper-constantan thermocouple probes. Water temperatures of the inner tubes are measured by mounting the thermocouple probes in the tubes. The flow of three working fluids hot water, normal water and cold water are maintained by the arrangement of three pumps in the heat exchanger.

Flow arrangements like N-H-C and C-H-N as suggested by G.A. Quadir et al.[14] are experimented. In N$\mathrm{H}-\mathrm{C}$ arrangement the normal water flows through the inner most pipe, hot water flows through the helical coil and the cold water flows through the helical annulus,

While in C-H-N arrangement, the cold water flows in the inner most pipe, the hot water flows in the helical coil and the normal water in helical annulus. To get the system into parallel flow condition all the three fluids flows in the same direction. In counter flow arrangement the flow direction of hot fluid in the helical tube is maintained in reverse direction, keeping the flow direction of the other two fluids same as in parallel flow condition. The outer fluid exchange heat with the surrounding as the outer surface of the heat exchanger is noninsulated and exposed to ambient. The water is pumped from the tank to the heat exchanger inlet. In its way to inlet a Rotameter is implanted to measure the volume flow rate. A valve is provided at the outlet of the pump to maintain the desired discharge. The fluid temperatures along the length of the heat exchanger are measured using 15 unit of thermocouple of type $\mathrm{T}$ copper-constantan. For each fluid two thermocouples are provided at entry and exit respectively. For each loop three thermocouples are placed between entry and exit point of heat exchanger at a gap of $0.5 \mathrm{~m}$ respectively. The system was allowed to steady state before any data were recorded, after reaching the steady state the thermocouples are connected to a Data Acquisition System (DAQ) which acquire and display simultaneously

\section{Result and discussions}

Experiments are carried out to study the temperature distribution along the length of triple concentric helical pipe heat exchanger for C-H-N and N-H-C fluid flow arrangement with non-insulated condition at the outer surface. All the data given in the present work are on the basis of average values of five numbers of experiments conducted.

III.1 Temperature distribution in N-H-C flow configuration:

The temperature variations of fluids along the length of the heat exchanger for N-H-C arrangement under parallel flow condition is presented in Figure 2, when the volume flow rate of cold and normal water are same $32.5 \mathrm{l} / \mathrm{min}$ and the hot water volume flow rate is $161 / \mathrm{min}$ at full throttle of the valve of hot water pipe . It is observed from Figure 2 that the hot water temperature drops to $30.45^{\circ} \mathrm{C}$ from its entry temperature of $59.8^{\circ} \mathrm{C}$, the normal water and the cold water temperatures are increased to $34.8^{\circ} \mathrm{C}$ and $22.4{ }^{\circ} \mathrm{C}$ respectively from their entry temperatures of $29.4^{\circ} \mathrm{C}$ and $13.3^{\circ} \mathrm{C}$ respectively due to the heat exchange between the working fluids. The rise in temperature of cold water is more than normal water due to higher heat transfer rate between hot fluid and cold fluid because of greater temperature difference between them. The temperature rise in cold water is further assisted by two causes- 1.larger heat transfer area available between the helical coil and outer annulus, 2 . Heat interaction between the ambient air and cold fluid .In this case the temperature variation curve for hot water intersects the temperature variation curve of normal water at a point known as cross over point. When the heat exchanger was operated in counter flow configuration, the volume flow rate of cold and normal water $32.5 \mathrm{l} / \mathrm{min}$ and hot water flow rate is $16 \mathrm{l} / \mathrm{min}$, under N-H-C arrangement, the temperature variation of three fluids along the length of the heat exchangers is shown in Figure 3. it is observed that the hot water temperature at outlet is $24.6^{\circ} \mathrm{C}$ from its entrance value of $59.6^{\circ} \mathrm{C}$, the normal water and the cold water temperatures are increased to $35.45^{\circ} \mathrm{C}$ and $29.8^{\circ} \mathrm{C}$ respectively from their entry temperatures of $28.3^{\circ} \mathrm{C}$ and $18.4^{\circ} \mathrm{C}$ respectively due to the heat exchange between the fluids.

Temperature rise in cold water is more than normal fluid and temperature gradient towards the end is steeper. This may be because of greater heat transfer rate as cold water flows in outer annulus and since it is noninsulated so heat leakage to ambient air. The counter flow configuration proved to be more effective with 


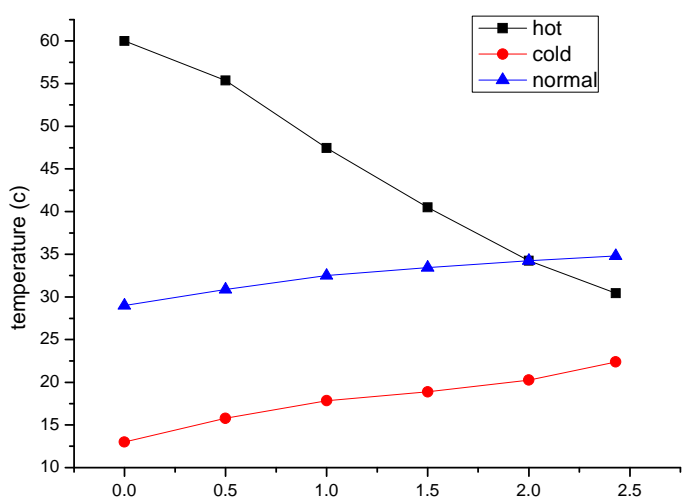

Fig.2 Parallel NHC flow full throttle

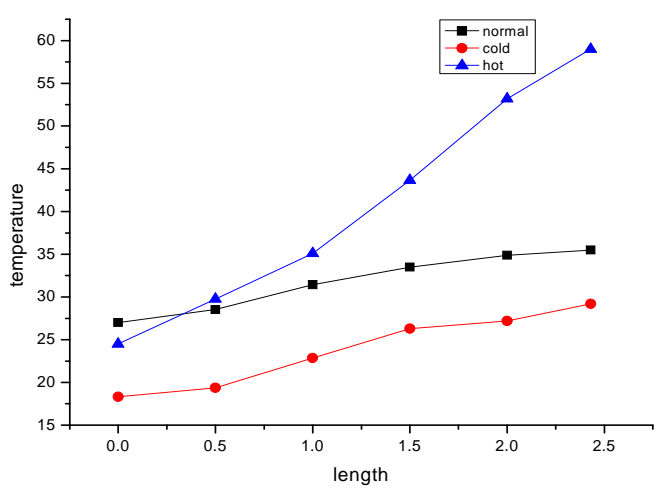

Fig. 3 Counter NHC flow full throttle

uniform temperature difference between hot and cold fluid as well as hot and normal fluid throughout the heat exchanger compared to parallel flow configuration. Hence heat flow rate of the three fluids is more in counter flow condition.

There is cross over point between the temperature variation curves of hot water and normal water nearly at the middle of the heat exchanger. As compared to the parallel flow condition the heat transfer rate is more in counter flow condition of heat exchanger.

III.2 Temperature variation in heat exchanger under C-H-N configuration:

In parallel flow, C-H-N configuration when the volume flow rate of hot water is $16 \mathrm{l} / \mathrm{min}$ and volume flow rate of cold and normal water are $32.51 / \mathrm{min}$, it is observed from Figure 4 that the hot water temperature falls to $31.25^{\circ} \mathrm{C}$ from its entry temperature of $59.72^{\circ} \mathrm{C}$, the normal water and the cold water temperatures are increases to $34.25^{\circ} \mathrm{C}$ and $20.25^{\circ} \mathrm{C}$ from their entry temperatures of $28.7^{\circ} \mathrm{C}$ and $12.9^{\circ} \mathrm{C}$ respectively.

It is observed that temperature variation throughout length of tube is more slant in normal fluid as it is flowing in outer annulus which is non-insulated. Hence there is heat transfer to surrounding. There is a crossover point between normal and hot fluid near $2 \mathrm{~m}$ length. Temperature of hot fluid still falls below that of normal fluid because of huge temperature difference in between cold and hot fluid.

For counter flow condition with full throttled condition, the temperature variations of three fluids are shown in Figure 5. The hot water temperature drops to $31.25^{\circ} \mathrm{C}$ from its inlet temperature of $58.7^{\circ} \mathrm{C}$, the normal and the cold fluid temperatures increases to $37.5^{\circ} \mathrm{C}$ and $24.8^{\circ} \mathrm{C}$ from their entry temperatures of $29.3^{\circ} \mathrm{C}$ and $18.4^{\circ} \mathrm{C}$ respectively. The temperature rise of normal and cold water are more in this arrangement as compared to the earlier case because temperature difference is more in counter flow arrangement.

From the above comparison it was concluded that counter flow gives better temperature fall in hot fluid as compared to parallel arrangement.

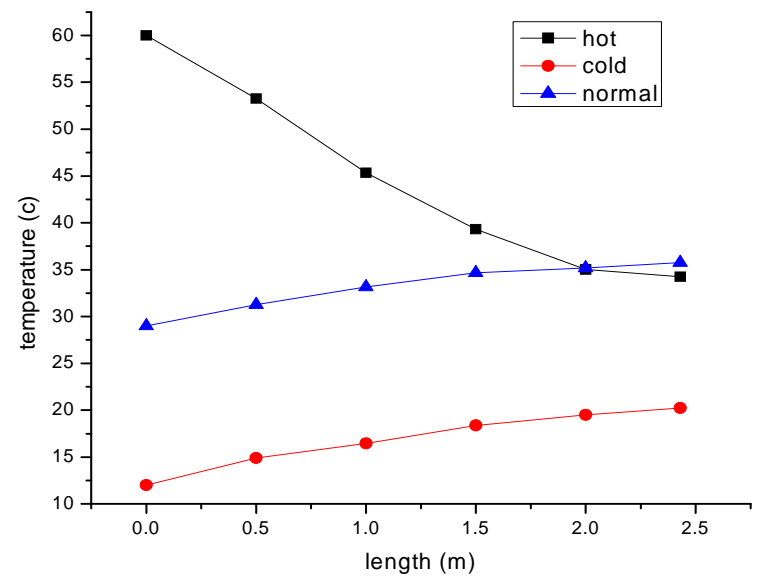

Fig.4. Parallel flow CHN arrangement.

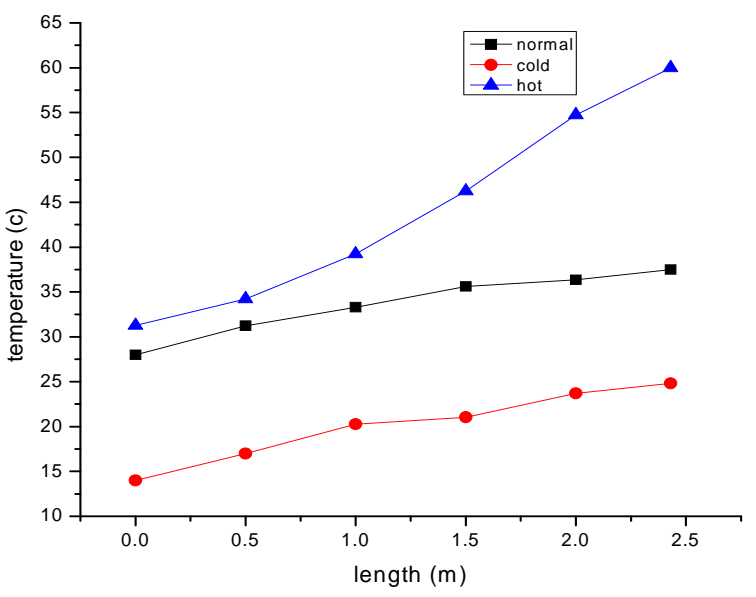

Fig.5. Counter flow CHN arrangements

III.3 Temperature variation w.r.t length for full throttle and half throttle in NHC arrangement:

From the above four cases of parallel and counter flow with NHC and CHN arrangements it is concluded that counter NHC gives better result in comparison to other types of flow arrangements. Further experiment was done with half throttle case for counter NHC flow arrangement. By reducing the volume flow rate, there is 
reduction in heat transfer coefficient which results in a lower heat transfer rate as being observed by the temperature $\mathrm{v} / \mathrm{s}$ tube length of the heat exchanger. It is observed where volume flow rate for the hot fluid is maintained at $8 \mathrm{l} / \mathrm{min}$, i.e. half throttle case and for cold and normal fluid the flow rate is maintained at 32.5 $1 / \mathrm{min}$ respectively The hot water temperature at outlet is $27.23^{\circ} \mathrm{C}$ from its inlet temperature of $59.1^{\circ} \mathrm{C}$ (Fig-6), whereas the hot water temperature at outlet is $24.6^{\circ} \mathrm{C}$ from its entrance value of $59.6^{\circ} \mathrm{C}$ for the full throttle case(Fig-7). The normal water and the cold water temperatures are increased to $34.32^{\circ} \mathrm{C}$ and $28.12^{\circ} \mathrm{C}$ from their entry temperatures of $29.4^{\circ} \mathrm{C}$ and $14.4^{\circ} \mathrm{C}$ respectively for half throttle one. The temperature rise of normal water and cold water are reduced as compared to earlier setup of $\mathrm{N}-\mathrm{H}-\mathrm{C}$ at full throttle where the normal water and the cold water temperatures are increased to $35.45^{\circ} \mathrm{C}$ and $29.8^{\circ} \mathrm{C}$ from their entry temperatures of $28.3^{\circ} \mathrm{C}$ and $18.4^{\circ} \mathrm{C}$ respectively.

From the figure it is observed that the hot fluid temperature gradient is steeper for half throttle case, but in case of full throttle the temperature curves are smoother. The reason is in half throttle case less flow rate condition caused the hot water temperature to decrease at a faster rate along half length of the heat exchanger and then the decrease in temperature slows down. Whereas in full throttle condition a smoother fall in temperature gradient is obtained throughout the length of the heat exchanger.

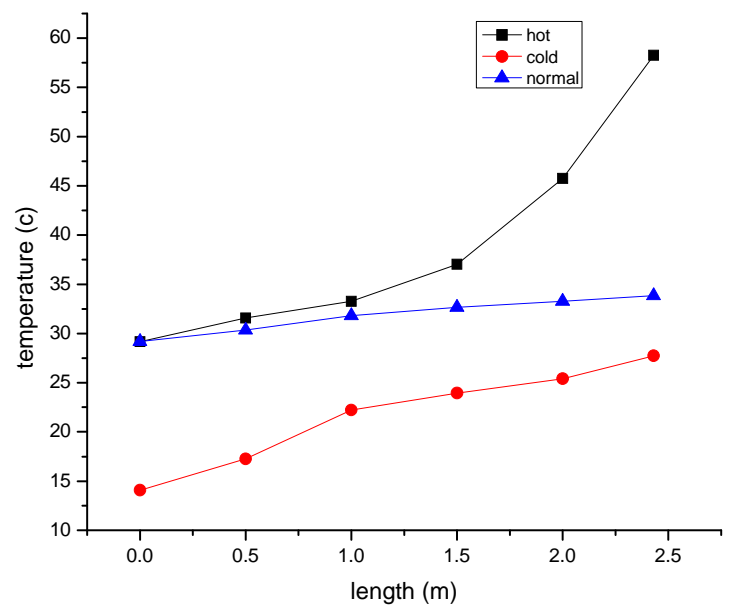

Fig.6. Half throttle NHC counter flow

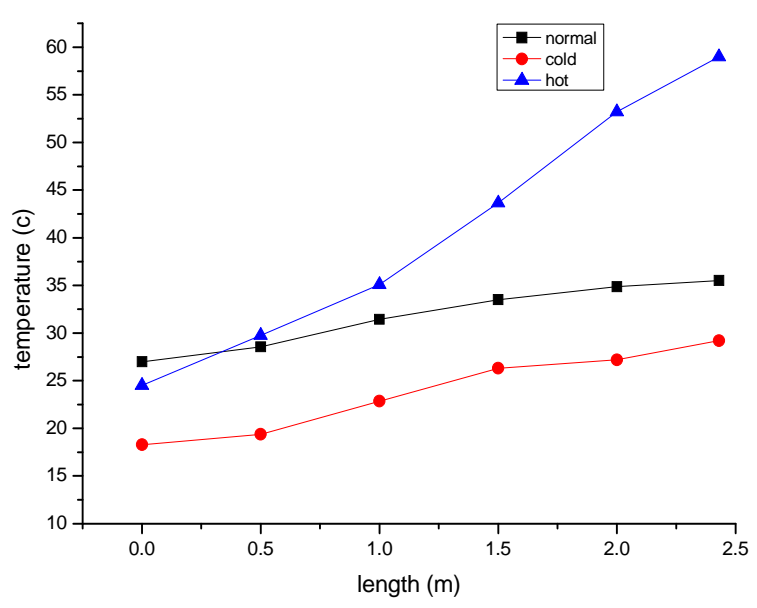

Fig. 7. Full throttle NHC counter flow

It is also seen that near the end of heat exchanger's length, there is a crossover point and the temperature of cold water is towards those temperatures. The temperature rise of normal and cold water are more in this arrangement as compared to the earlier case of half throttle because the log mean temperature difference is more in counter flow arrangement. The reduced mass flow rate of hot water reduces the convective heat transfer coefficient on hot water side thus reducing the heat transfer rate from hot water.

\section{III.4 Effectiveness of heat exchanger}

The effectiveness of heat exchanger was calculated for all the flow arrangements. The effectiveness of heat exchanger depends upon the mass flow rate of fluid, temperature difference between the flowing fluids and heat transfer surface. The effectiveness is compared for parallel v/s counter flow (fig. 8) CHN arrangement and for $\mathrm{NHC} \mathrm{v} / \mathrm{s}$ CHN counter flow condition in fig. 9. Also for half throttle and full throttle condition for NHC arrangement is presented in fig. 10. The heat exchanger effectiveness can be calculated by using the equation 1 . [11].

$\varepsilon=\frac{\dot{\mathrm{Q}}}{\mathrm{Q} m a x}$

is the actual heat transfer rate and $\mathrm{Qmax}_{\text {is }}$ the maximum possible heat transfer rate of heat exchanger as per expressions [11].

$\dot{\mathrm{Q}}=\mathrm{C}_{\mathrm{h}}\left(\mathrm{T}_{\mathrm{h}, \mathrm{i}}-\mathrm{T}_{\mathrm{h}, \mathrm{o}}\right)$

$\dot{\mathrm{Q}} \max =\mathrm{C}_{\min }\left(\mathrm{T}_{\mathrm{h}, \mathrm{i}}-\mathrm{T}_{\mathrm{c}, \mathrm{i}}\right)$

$$
\mathrm{C}_{\min }=\left\{\begin{array}{lll}
C_{h} & \text { if } & C_{h} \leq C_{n}+C_{c} \\
C_{n}+C_{c} & \text { if } & C_{h} \geq C_{n}+C_{c}
\end{array}\right.
$$


Where $C_{c}, C_{h}$ and $C_{n}$ are the heat capacity rate of cold fluid side, hot fluid side and normal fluid side respectively and $\mathrm{C}_{\min }$ is the minimum capacity rate. $\mathrm{T}_{\mathrm{h}, \mathrm{i}}$ and $\mathrm{T}_{\mathrm{h}, \mathrm{o}}$ are the temperatures of hot water inlet and hot water outlet respectively, $T_{c, i}$ is the temperature of cold water inlet.

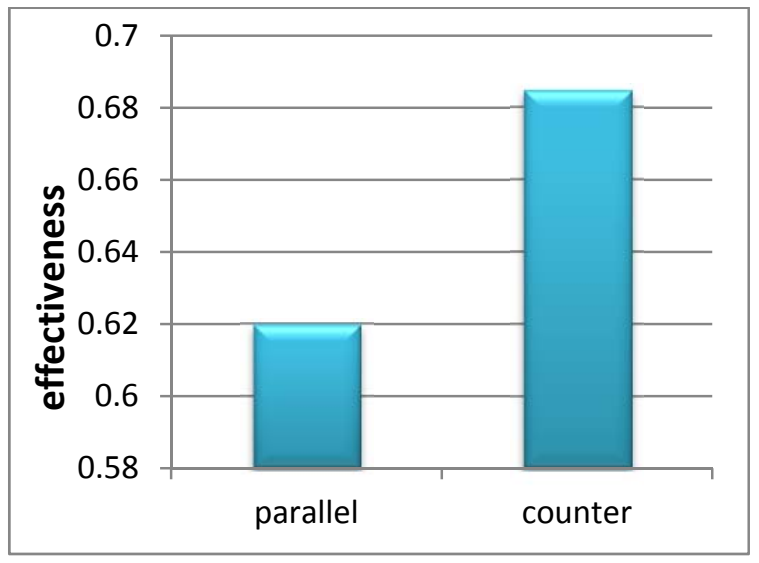

Fig. 8. Effectiveness of CHN full throttle

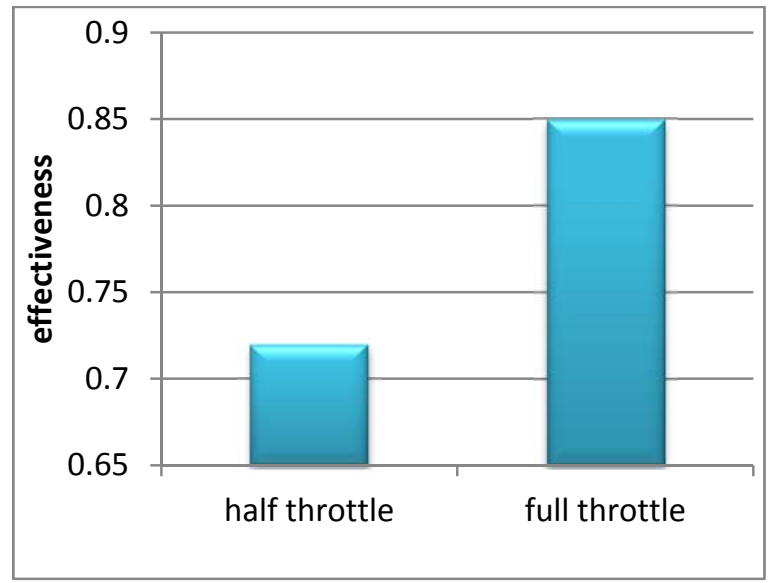

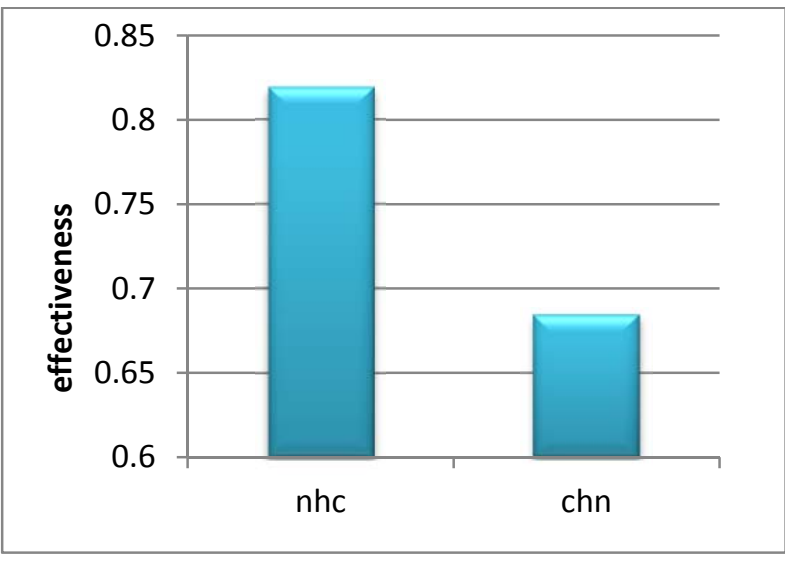

Fig.9. Effectiveness of $\mathrm{NHC}$ v/s $\mathrm{CHN}$ counter full throttle

Fig.10. Effectiveness of NHC arrangement half throttle

From the graph it was found that in NHC arrangement effectivenss of the heat exchanger is much more than CHN arrangement due to large temperature difference between cold and hot fluid and large heat transfer area. In case of counter flow arrangement the effectiveness was found to be better as compared to parallel flow arrangement. Further by comparing half throttle and full throttle conditions it was found that the heat exchanger effectiveness was better in case of full throttle condition. This is due to increase in volume flow rate, results in increased overall heat transfer coefficient and better heat transfer rate.

\section{CONCLUSIONS}

An experimental set up of helical triple concentric pipe heat exchanger is proposed, fabricated and experimented to study the heat exchange behaviour between the three fluids (normal, hot and cold water) under different operating condition. The results are presented in terms of temperature variation of three fluids along the length of heat exchanger. Effectiveness of heat exchanger at different flow arrangement is also compared. The N-H-C and $\mathrm{C}-\mathrm{H}-\mathrm{N}$ flow arrangement are studied for the heat exchanger. In both C-H-N and N-H-C arrangement, parallel as well as counter flow of hot fluid in helical pipe was tested for different arrangements. Experiments are also conducted at different volume flow rate of hot fluid.

The following observation and conclusion are drawn from the experiment:

I. The N-H-C arrangement of flow is more effective and has more heat transfer rate than the C-H-N arrangement for both parallel and counter flow conditions. 
II. In case of parallel flow heat exchangers cross over points are observed for temperature distribution $\mathrm{v} / \mathrm{s}$ length because all the three fluids are flowing in same direction and more heat interaction occurring between cold and hot fluid due to greater temperature difference.

III. N-H-C, counter flow, full throttle configuration proved as the best arrangement of fluid flow among the other types of experimented arrangements.

IV. The effectiveness of the heat exchanger is higher up to $20 \%$ in $\mathrm{N}-\mathrm{H}-\mathrm{C}$ counter flow full throttle condition as compared to C-H-N counter flow full throttle condition and $28 \%$ more than C-H-N parallel flow which has the lowest value of effectiveness.

V. The effectiveness of NHC counter flow full throttle is $16.23 \%$ more than the counter flow half throttle case.

\section{REFERENCES}

[1] L. Godson, K. Deepak, C. Enoch, B. Jefferson, B. Raja. Heat transfer characteristics of silver/water nanofluids in a shell and tube heat exchanger, archives of civil and mechanical engineering.14(2014)489-496.

[2] Xiang-hui Tan, Dong-sheng Zhu, Guo-yan Zhou, Liu Yang. 3D numerical simulation on the shell side heat transfer and pressure drop performances of twisted oval tube heat exchanger. International Journal of Heat and Mass Transfer 65 (2013) $244-253$.

[3] Xiang-hui Tan, Dong-sheng Zhu, Guo-yan Zhou, Li-ding Zeng,Heat transfer and pressure drop performance of twisted oval tube heat exchanger. Applied Thermal Engineering 50 (2013) 374-383.

[4] L. Cheng, T. Luan, W. Du, M. Xu. Heat transfer enhancement by flow-induced vibration in heat exchangers. International Journal of Heat and Mass Transfer 52 (2009) 1053-1057.

[5] N. Sahiti, F. Durst, A. Dewan. Heat transfer enhancement by pin elements. International Journal of Heat and Mass Transfer 48 (2005) $4738-4747$.

[6] H.A. Mohammed, Husam A. Hasan , M.A. Wahid. Heat transfer enhancement of nanofluids in a double pipe heat exchanger with louvered strip inserts. Int. J. Heat Mass Transfer 40 (2013) 36-46.

[7] E.K. Akpinar, Y. Bicer. Investigation of heat transfer and exergy loss in a concentric double pipe exchanger equipped with swirl generators. Int. J. Thermal Sci. 44 (Jun 2005) 598-607.

[8] PaisarnNaphon. Second law analysis on the heat transfer of the horizontal concentric tube heat exchanger. International Communications in Heat and Mass Transfer 33 (2006) 1029-1041.

[9] B. Yu, J.H. Nie, Q.W. Wang, W.Q. Tao. Experimental study on the pressure dropand heat transfer characteristics of tubes with internal wave-like longitudinal fins. Heat Mass Transfer 35 (1999) 65-73.

[10] A.Unal. Theoretical analysis of triple concentric-tube heat exchangers Part 1: Mathematical modelling. Int. Commun. Heat Mass Transfer 25 (Oct 1998) 949-958.

[11] Unal. Theoretical analysis of triple concentric-tube heat exchangers Part 2: Case studies. Int. Commun. Heat Mass Transfer 28 (Feb 2001) 243-256.

[12] Birol Basal, AhmetUnal. Numerical evaluation of triple concentric-tube latent heatthermal energy storage. Solar Energy 92 (2013) 196-205.

[13] G.A. Quadir, SaqabS.Jarallah, N.J.Salman Ahmed, IrfanAnjumBadruddin. Experimental investigation of the performance of a triple concentric pipe heat exchanger. Int. Journal of Heat and Mass Transfer 62 (2013) 562-566.

[14] Zan Wu, Lei Wang, BengtSunden. Pressure drop and convective heat transfer of water and nanofluids in a double-pipe helical heat exchanger. Applied Thermal Engineering.(Jun 2013).

[15] N. Jamshidi, M. Farhadi, D.D. Ganji, K. Sedighi. Experimental analysis of heat transfer enhancement in shell and helical tube heat exchangers. Applied Thermal Engineering 51 (2013) 644-652.

[16] Nasser Ghorbani, HessamTaherian,MofidGorji,HessamMirgolbabaei. An experimental study of thermal performance of shell-and-coil heat exchangers. International Communications in Heat and Mass Transfer 37 (2010) 775-781.

[17] Yang Dong, Li Huixiong, Chen Tingkuan. Pressure drop, heat transfer and performance of single-phase turbulent flow in spirally corrugated tubes. Experimental Thermal and Fluid Science 24(2001)131-138.

[18] EbruKavakAkpinar. Evaluation of heat transfer and exergy loss in a concentric double pipe exchanger equipped with helical wires.47(2006)3473-3486.

[19] Incropera, P.I., and De Witt,D.P. Introduction to Heat Transfer, 1st ed.,p.464, Wiley,New York(1985).

[20] V.M. Behera, D.H. Das, Ayusman Nayak. Numerical Analysis Of Triple Tube Heat Exchanger Using Ansys,International Journal Of Scientific \& Engineering Research 5(2014) 1226-1231.

\section{AUTHOR PROFILE}

Monalisa Sahoo Assistant Professor in BEC,BBSR, Odisha.

Vishwa mohan Behera, Assistant Professor in BEC,BBSR, Odisha.

Dr. Sankar Narayan Das, Assistant Professor in ITER, SOA University, Odisha

Dr. Harish Chandra Das, Professor in ITER, SOA University, Odisha 